Sciendo

\title{
On What There Must Be: \\ Existence in Logic and Some Related Riddles
}

\author{
Paulo A. S. Veloso, Federal University of Rio de Janeiro \\ Luiz Carlos Pereira, Pontifical Catholic University of Rio de Janeiro \\ E. Hermann Haeusler, Pontifical Catholic University of Rio de Janeiro
}

Disputatio Vol. 4, No. 34

December 2012

DOI: $10.2478 /$ disp-2012-0036

ISSN: 0873-626X 


\section{On What There Must Be: Existence in Logic and Some Related Riddles}

Paulo A. S. Veloso

Federal University of Rio de Janeiro

Luiz Carlos Pereira

Pontifical Catholic University of Rio de Janeiro

E. Hermann Haeusler

Pontifical Catholic University of Rio de Janeiro

BIBLID [0873-626X (2012) 34; pp. 889-910]

\section{Introduction}

It is part of an old folklore that logic should not have existential theorems or existential validities. One should not prove in pure logic the existence of anything whatsoever; nothing could be proved by means of logic alone to necessarily exist. Whatever exists might not exist. This standpoint has been expressed by several philosophers from different traditions, such as Hume, Kant, Orenstein and Quine. ${ }^{1}$

We now set the stage by examining some issues. Our main question is: "Do we actually have existential theorems in logic?" Two possible attitudes towards this question are as follows.

\footnotetext{
${ }^{1}$ See for instance, Hume's Dialogue on Natural Religion [Hum92] (Part IX, 189), the introduction to Kant/Jäsche [Kan92], Orenstein [Ore73] (p. 62) and Quine [Qui54].

Disputatio, Vol. IV, No. 34, December 2012
} 
- A desideratum: logic should not have any existential theorems.

- A fact: logic does not have any existential theorems.

An intuitive explanation for these attitudes can be roughly as follows. Consider an existential assertion, such as "there exist borogroves", or "something is a borogrove". Such an assertion may perhaps be derived from some hypotheses. But, could it be proved, from no hypothesis whatsoever? In this context, one has absolutely no idea about what 'borogrove' is supposed to mean. ${ }^{2}$ So, one can appeal only to logical principles. How would such a proof look like? Here, the problem seems to stem from the fact that we do not know what 'borogrove' is supposed to mean. How can one establish some property of something whose meaning is unknown? Well, actually we can: we do know that "something is a borogrove or a non-borogrove". One might contend that this assertion is not really about borogroves: it expresses a general fact.

The above attitudes towards existential theorems in logic lead to the following slogans concerning (First-order) Logic.

1. No existential conclusion without (perhaps alternative) witnesses.

2. No existential conclusion without universal explanation.

Crudely formulated as above, the preceding attitudes and slogans are clearly misplaced and false: first-order logic does have existential theorems. Our slogans seem to originate from the absence of existential commitments in logic. Well, in a sense, logic does make the following commitments. ${ }^{3}$

${ }^{2}$ Note that a definition of 'borogrove' or other elucidations will not be of much help here. First, they would be counted as hypotheses. Second, if one explains 'borogroves' as, say, "those things that are nimsy", one is bringing 'nimsy' into the picture, and we are back to the same question.

${ }^{3}$ These commitments are incorporated in the introduction rule for the existential quantifier. 
(Cnst) One usually assumes that constant symbols denote elements of the universe; so the existential sentence $\exists \mathrm{zz} \doteq \mathrm{c}$ is valid. ${ }^{4}$

(Fnc) Similarly, function symbols represent total functions on the universe; so the existential sentence $\exists \mathrm{x} \exists \mathrm{y} y \doteq \mathrm{f}(\mathrm{x})$ is valid.

Now, consider First-order Predicate Logic with no constants or functions. One may perhaps still detect an existential commitment in the fact that Logic usually considers only nonempty universes. Even if the existence of any particular object is contingent, it is necessary that something exists. The laws of logic are abstract in the sense that they do not presuppose particular objects, but they are not abstract in the sense that they do not presuppose objects. This commitment renders valid the existential sentence $\exists \mathrm{zz} \doteq \mathrm{z} .{ }^{5}$ Under this modest existential commitment the slogan we propose is: Pure Logic cannot establish existence unless unavoidable. ${ }^{6}$

The structure of this paper is as follows. Section 2 considers the simple case of predicate logic without equality. Section 3 examines the case of predicate logic with equality. Section 4 extends these considerations to the case of universal hypotheses (as axioms). In Section 5, we briefly consider the addition of existential hypotheses. Finally, in Section 6, we summarize our results, commenting on them as well as on some possible extensions.

\section{Predicate logic without equality}

We now examine the case of predicate logic without equality.

We begin with some simple examples of valid and non-valid sentences.

${ }^{4}$ An assertion like "Pegasus is a winged horse" may be paraphrased as "something identical to Pegasus is a winged horse". Also, "Aristotle is Greek" yields "There are Greeks".

${ }^{5}$ It is this modest commitment that allows one to infer $\exists v \varphi$ from $\forall \mathrm{v} \varphi$, e.g. "Every natural is non-negative" yields "Some natural is non-negative".

${ }^{6}$ The easy road to avoid existential theorems is, of course, to allow empty domains: with empty universes, one would have no existential validity. In in this paper, we take the hard road: even if empty domains are not excluded, predicate logic should not have any existential theorems. 
1. Given a unary predicate (symbol) p, consider the matrix $\mathrm{p}(\mathrm{z}) \rightarrow \mathrm{p}(\mathrm{z})$. In this case, the existential sentence $\exists \mathrm{z}(\mathrm{p}(\mathrm{z}) \rightarrow \mathrm{p}(\mathrm{z}))$ is valid, and so is the universal sentence $\forall \mathrm{z}(\mathrm{p}(\mathrm{z}) \rightarrow \mathrm{p}(\mathrm{z}))$ valid.

2. Now, given yet another unary predicate (symbol) q, consider the matrix $\mathrm{p}(\mathrm{z}) \rightarrow \mathrm{q}(\mathrm{z})$. In this case, the existential sentence $\exists \mathrm{z}(\mathrm{p}(\mathrm{z}) \rightarrow \mathrm{q}(\mathrm{z}))$ is non-valid, and so is the universal sentence $\forall \mathrm{z}(\mathrm{p}(\mathrm{z}) \rightarrow \mathrm{q}(\mathrm{z}))$ non-valid.

These two examples illustrate the following situations.

1. For the matrix $\mathrm{p}(\mathrm{z}) \rightarrow \mathrm{p}(\mathrm{z})$, we have:

$$
\begin{array}{lcl}
\text { existential sentence } & \exists \mathrm{z}(\mathrm{p}(\mathrm{z}) \rightarrow \mathrm{p}(\mathrm{z})) & \text { valid } \\
\text { matrix } & \mathrm{p}(\mathrm{z}) \rightarrow \mathrm{p}(\mathrm{z}) & \text { tautological } \\
\text { universal sentence } & \forall \mathrm{z}(\mathrm{p}(\mathrm{z}) \rightarrow \mathrm{p}(\mathrm{z})) & \text { valid }
\end{array}
$$

2. For the matrix $\mathrm{p}(\mathrm{z}) \rightarrow \mathrm{q}(\mathrm{z})$, we have:

$\begin{array}{lcl}\text { existential sentence } & \exists \mathrm{z}(\mathrm{p}(\mathrm{z}) \rightarrow \mathrm{q}(\mathrm{z})) & \text { non-valid } \\ \text { matrix } & \mathrm{p}(\mathrm{z}) \rightarrow \mathrm{q}(\mathrm{z}) & \text { non-tautological } \\ \text { universal sentence } & \forall \mathrm{z}(\mathrm{p}(\mathrm{z}) \rightarrow \mathrm{q}(\mathrm{z})) & \text { non-valid }\end{array}$

These situations may suggest a simple, albeit tentative, explanation. Now, let us examine some other examples of valid and non-valid sentences.

Given a unary predicate (symbol) p, consider the matrix $\mathrm{p}(\mathrm{y}) \rightarrow \mathrm{p}(\mathrm{z})$. In this case, notice that the existential sentence $\exists \mathrm{y} \exists \mathrm{z}(\mathrm{p}(\mathrm{y}) \rightarrow \mathrm{p}(\mathrm{z}))$ is still valid, but the universal sentence $\forall \mathrm{y} \forall \mathrm{z}(\mathrm{p}(\mathrm{y}) \rightarrow \mathrm{p}(\mathrm{z}))$ not valid. There is, however, a way out: the variant versions. We will then have the following situation: 


$$
\begin{array}{lrl}
\text { Existential variant } & \exists \mathrm{y} \exists \mathrm{z}\left[\begin{array}{c}
(\mathrm{p}(\mathrm{y}) \rightarrow \mathrm{p}(\mathrm{z})) \\
\vee \\
(\mathrm{p}(\mathrm{z}) \rightarrow \mathrm{p}(\mathrm{z}))
\end{array}\right] & \text { valid } \\
\text { Universal variant } & \forall \mathrm{y} \forall \mathrm{z}\left[\begin{array}{c}
(\mathrm{p}(\mathrm{y}) \rightarrow \mathrm{p}(\mathrm{z})) \\
\vee \\
(\mathrm{p}(\mathrm{z}) \rightarrow \mathrm{p}(\mathrm{z}))
\end{array}\right] \quad \text { valid }
\end{array}
$$

These two variants are valid, due to the disjunct $\mathrm{p}(\mathrm{z}) \rightarrow \mathrm{p}(\mathrm{z})$; they have the matrix

$$
\left[\begin{array}{c}
(\mathrm{p}(\mathrm{y}) \underset{\mathrm{p}(\mathrm{z}))}{\vee} \\
(\mathrm{p}(\mathrm{z}) \underset{\mathrm{p}(\mathrm{z}))}{\rightarrow}
\end{array}\right] \quad \text { valid }
$$

Now, given a binary predicate (symbol) $\mathrm{r}$, consider the matrix $\mathrm{r}(\mathrm{y}, \mathrm{z})$ . In this case, neither the existential sentence $\exists \mathrm{y} \exists \mathrm{zr}(\mathrm{y}, \mathrm{z})$ nor the universal sentence $\forall \mathrm{y} \forall \mathrm{zr}(\mathrm{y}, \mathrm{z})$ is valid. The situation with their variant versions is as follows:

$$
\begin{array}{lll}
\text { Existential variant } & \exists y \exists z\left[\begin{array}{c}
r(y, z) \\
\vee \\
r(z, z)
\end{array}\right] \quad \text { not valid } \\
\text { Universal variant } & \forall y \forall z\left[\begin{array}{c}
r(y, z) \\
\vee \\
r(z, z)
\end{array}\right] \quad \text { not valid }
\end{array}
$$

Now, the disjuncts $\mathrm{r}(\mathrm{y}, \mathrm{z})$ and $\mathrm{r}(\mathrm{z}, \mathrm{z})$ are non-valid, and so is non-valid the matrix

$$
\left.\left[\begin{array}{c}
r(y, z) \\
V \\
r(z, z)
\end{array}\right] \quad \text { (e.g. interpret } r:=\emptyset\right)
$$

Let us summarize the ideas seen in our examples. 
- Given a matrix, $M(\mathrm{y}, \mathrm{z})$, we may have the existential sentence $\exists \mathrm{y} \exists \mathrm{z} M(\mathrm{y}, \mathrm{z})$ valid and the universal sentence $\forall \mathrm{y} \forall \mathrm{z} M(\mathrm{y}, \mathrm{z})$ not valid.

- The examples suggest some simple syntactical transformations as follows.

(SM) The singular matrix $M(\mathrm{z}, \mathrm{z})$, obtained from the original matrix $M(\mathrm{y}, \mathrm{z})$ by replacing every variable by $\mathrm{z}$.

(VM) The variant matrix $M(\mathrm{y}, \mathrm{z}) \vee M(\mathrm{z}, \mathrm{z})$, obtained by weakening the original matrix $M(\mathrm{y}, \mathrm{z})$ by the singular disjunct $M(\mathrm{z}, \mathrm{z})$.

One can see that the variant matrix follows from the original one:

$$
\underbrace{M(\mathrm{z}, \mathrm{z})}_{\mathrm{SM}} \vdash^{(\mathrm{Vl})} \underbrace{M(\mathrm{y}, \mathrm{z}) \vee M(\mathrm{z}, \mathrm{z})}_{\mathrm{VM}} \quad(\mathrm{V} \text {-introduction). }
$$

Our examples seem to suggest the following conjectures.

1. Weakening does not affect existential sentence:

$$
\frac{\exists \mathrm{y} \exists \mathrm{z} M(\mathrm{y}, \mathrm{z})}{\text { valid }} \Leftrightarrow \frac{\exists \mathrm{y} \exists \mathrm{z}[M(\mathrm{y}, \mathrm{z}) \vee M(\mathrm{z}, \mathrm{z})]}{\text { valid }}
$$

2. Propositional reduction for existential validity:

$$
\frac{\exists \mathrm{y} \exists \mathrm{z} M(\mathrm{y}, \mathrm{z})}{\text { valid }} \Rightarrow \frac{M(\mathrm{z}, \mathrm{z})}{\text { tautology }}
$$

3. Tautological variant matrix gives universal variant valid:

$$
\frac{M(\mathrm{z}, \mathrm{z}) \vee M(\mathrm{y}, \mathrm{z})}{\text { tautology }} \Rightarrow \quad \frac{\forall \mathrm{y} \forall \mathrm{z}[M(\mathrm{y}, \mathrm{z}) \vee M(\mathrm{z}, \mathrm{z})]}{\text { valid }}
$$

4. Universal variant yields existential sentence:

$$
\frac{\forall \mathrm{y} \forall \mathrm{z}[M(\mathrm{y}, \mathrm{z}) \vee M(\mathrm{z}, \mathrm{z})]}{\text { valid }} \Rightarrow \quad \frac{\exists \mathrm{y} \exists \mathrm{z} M(\mathrm{y}, \mathrm{z})}{\text { valid }}
$$


We now examine these four conjectures.

1. The equivalence between $\exists \mathrm{y} \exists \mathrm{z} M(\mathrm{y}, \mathrm{z})$ and $\exists \mathrm{y} \exists \mathrm{z}[M(\mathrm{y}, \mathrm{z}) \vee M(\mathrm{z}, \mathrm{z})]$ is easy to see (by the rules for $\exists$ and $\vee)$.

2. The idea is considering single-element structures (see below).

3. The assertion follows (by $\forall$-introductions: if $\vdash N$ then $\vdash \forall \mathrm{v} N)$.

4. The assertion follows from the first assertion (since $\forall \vdash \exists$ ).

Let us take a closer look at the propositional reduction for existential theorems. There are two ways to establish this reduction, by singularization. ${ }^{7}$

- For classical logic, we consider single-element structures. In such a structure, there are no actual quantifiers: $\exists \mathrm{y} \exists \mathrm{z} M(\mathrm{y}, \mathrm{z})$ holds iff $M(\mathrm{y}, \mathrm{z})$ holds for the single element iff $\forall \mathrm{y} \forall \mathrm{z} M(\mathrm{y}, \mathrm{z})$ holds.

- Also, one can show that a predicate-logic proof of $\exists \mathrm{y} \exists \mathrm{z} M(\mathrm{y}, \mathrm{z})$ may be reduced to a propositional proof $\Pi_{\mathrm{z}}$ of $M(\mathrm{z}, \mathrm{z})$ followed by $\exists$-introductions:

$$
\text { (ᄏl) } \frac{\stackrel{\Pi}{\mathrm{z}} \frac{M(\mathrm{z}, \mathrm{z})}{\exists \mathrm{z} M(\mathrm{y}, \mathrm{z})}}{\exists \mathrm{y} \exists \mathrm{z} M(\mathrm{y}, \mathrm{z})}
$$

Indeed, we can transform a predicate-logic derivation $\Pi$ to a propositional derivation $\Pi_{z}$ by singularizing it. If we replace every variable by $\mathrm{z}$ and erase all quantifiers, we transform both $\forall \mathrm{y} N(\mathrm{x}, \mathrm{y})$ and $\exists \mathrm{y} N(\mathrm{x}, \mathrm{y})$ to $N(\mathrm{z}, \mathrm{z})$. So, connective rules remain unaffected and likewise for the absurdity rules. The quantifiers rules become repeti-

\footnotetext{
${ }^{7}$ Such singular translations appear in the litterature, e.g. "réduction de genre un" [Cha79, p.119-123]. They are often used to establish the relative consistency of predicate logic with respect to propositional logic [End72, p.59].
} 
tions, except for $\exists$-elimination, which reduces to derivation gluing. In detail:

- For the quantifier introduction rules, we have:
$\forall \mathrm{v} P(\mathrm{u}, \mathrm{v}) \quad P(\mathrm{z}, \mathrm{z})$
$\Pi \quad \Rightarrow \quad \Pi_{z}$
$(\forall \mathrm{I}) \frac{R(\mathrm{x}, \mathrm{y})}{\forall \mathrm{y} R(\mathrm{x}, \mathrm{y})} \quad \begin{gathered}R(\mathrm{z}, \mathrm{z}) \\ \| \\ R(\mathrm{z}, \mathrm{z})\end{gathered}$
$\forall \mathrm{v} P(\mathrm{u}, \mathrm{v}) \quad P(\mathrm{z}, \mathrm{z})$
$\Pi \quad \Rightarrow \quad \Pi_{\mathrm{z}}$
(키) $\frac{R(\mathrm{x}, \mathrm{w})}{\exists \mathrm{y} R(\mathrm{x}, \mathrm{y})}$
$R(\mathrm{z}, \mathrm{z})$
$R(\mathrm{z}, \mathrm{z})$

- For the elimination of $\forall$, we have:

$$
\begin{array}{ccc}
\forall \mathrm{v} P(\mathrm{u}, \mathrm{v}) & & P(\mathrm{z}, \mathrm{z}) \\
\Pi & \Pi_{\mathrm{z}} \\
(\forall \mathrm{E}) \frac{\forall \mathrm{y} R(\mathrm{x}, \mathrm{y})}{R(\mathrm{x}, \mathrm{w})} & & R(\mathrm{z}, \mathrm{z}) \\
& & \| \\
& & R(\mathrm{z}, \mathrm{z})
\end{array}
$$

- For the elimination of $\exists$, we have:

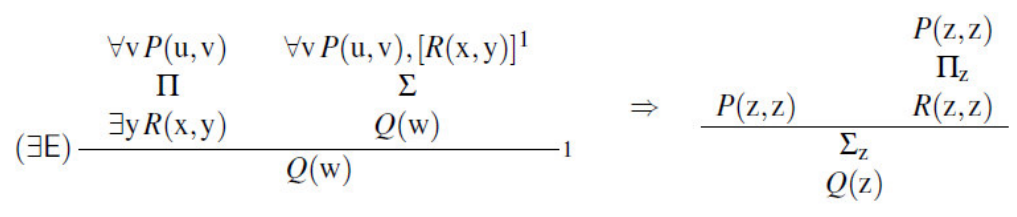

We then have the following proof transformation:

$$
\begin{gathered}
\emptyset \\
\exists \\
\exists \mathrm{y} \exists \mathrm{z} M(\mathrm{y}, \mathrm{z})
\end{gathered} \quad \Rightarrow \quad \begin{gathered}
\emptyset \\
\Pi_{\mathrm{z}} \\
M(\mathrm{z}, \mathrm{z})
\end{gathered}
$$

We thus have the following characterizations for the provable existential sentences in Classical, Intuitionistic or Minimal Logics without equality $\doteq$.

Theorem 2.1. The following assertions are equivalent for a matrix $M(\mathrm{y}, \mathrm{z})$.

$\left(P_{1} E S\right)$ the existential sentence is provable in predicate logic: $\vdash_{1} \exists \mathrm{y} \exists \mathrm{z} M(\mathrm{y}, \mathrm{z})$. 
$\left(P_{1} E V\right)$ The existential variant is a theorem: $\vdash_{1} \exists \mathrm{y} \exists \mathrm{z}[M(\mathrm{y}, \mathrm{z}) \vee M(\mathrm{z}, \mathrm{z})]$.

$\left(P_{0} S M\right)$ The singular matrix is provable in propositional logic: $\vdash_{0} M(\mathrm{z}, \mathrm{z})$.

$\left(P_{1} U V\right)$ The universal variant is a theorem: $\vdash_{1} \forall \mathrm{y} \forall \mathrm{z}[M(\mathrm{y}, \mathrm{z}) \vee M(\mathrm{z}, \mathrm{z})]$.

Thus, the existential sentences $\exists \mathrm{y} \ldots \exists \mathrm{z} M(\mathrm{y}, \ldots, \mathrm{z})$, without equality, that are provable in predicate logic are exactly those having both:

- a universal explanation

$\left(\vdash_{1} \forall \mathrm{y} \ldots \forall \mathrm{z}[M(\mathrm{y}, \ldots, \mathrm{z}) \vee M(\mathrm{z}, \ldots, \mathrm{z})]\right)$,

- $\quad$ witnesses $\left(\vdash_{0} M(\mathrm{z}, \ldots, \mathrm{z})\right)$.

\section{Predicate logic with equality}

We now examine the case of predicate logic with equality.

We begin with some simple examples of valid and non-valid sentences.

1. First, consider the matrix $\mathrm{z} \doteq \mathrm{z}$. In this case, the existential sentence $\exists \mathrm{zz} \doteq \mathrm{z}$ is valid, and so is the universal sentence $\forall \mathrm{zz} \doteq \mathrm{z}$ valid.

2. Next, consider the matrix $\neg \mathrm{Z} \doteq \mathrm{z}$. Then, the existential sentence $\exists \mathrm{z} \neg \mathrm{z} \doteq \mathrm{z}$ is non-valid, and so is the universal sentence $\forall \mathrm{z} \neg \mathrm{z} \doteq \mathrm{z}$ non-valid.

3. Finally, consider the matrix $y \doteq z$. In this case, the existential sentence $\exists \mathrm{y} \exists \mathrm{z} y \doteq \mathrm{z}$ is valid, but the universal sentence $\forall \mathrm{y} \forall \mathrm{zy} \doteq \mathrm{z}$ is not valid. Now, the universal variant is the sentence $\forall \mathrm{y} \forall \mathrm{z}[\mathrm{z} \doteq \mathrm{z} \vee \mathrm{y} \doteq \mathrm{z}]$, which is valid.

So, the situation is much as before. For a propositional explanation, one must take into account the special nature of the equality sign: $\doteq$ is to interpreted as identity. So, it has some properties embodied in the rules and axioms for equality. 


$\begin{array}{lcc}\text { Property } & \underline{\text { Rule }} & \underline{\text { Axiom }} \\ \text { Reflexive } & (\rho) \frac{\mathrm{u} \doteq \mathrm{u}}{\mathrm{u}} & \mathrm{u} \\ \text { Symmetric } & (\sigma) \frac{\mathrm{u} \doteq \mathrm{v}}{\mathrm{v} \doteq \mathrm{u}} & \forall \mathrm{u} \forall \mathrm{v}\left(\begin{array}{c}\mathrm{u} \doteq \mathrm{v} \\ \downarrow \\ \mathrm{v} \doteq \mathrm{u}\end{array}\right) \\ \text { Transitive } & (\tau) \frac{\mathrm{u} \doteq \mathrm{v} \mathrm{v} \doteq \mathrm{w}}{\mathrm{u} \doteq \mathrm{w}} & \forall \mathrm{u} \forall \mathrm{v} \forall \mathrm{w}\left[\begin{array}{c}(\mathrm{u} \doteq \mathrm{v} \wedge \mathrm{v} \doteq \mathrm{w}) \\ \downarrow \\ \mathrm{u} \doteq \mathrm{w}\end{array}\right] \\ \text { Congruence } & (\mathrm{\kappa}) \frac{\mathrm{u} \doteq \mathrm{v} \mathrm{p}(\mathrm{u})}{\mathrm{p}(\mathrm{v})} & \forall \mathrm{u} \forall \mathrm{v}\left[\begin{array}{c}(\mathrm{u} \doteq \mathrm{v} \wedge \mathrm{p}(\mathrm{u})) \\ \downarrow \\ \mathrm{p}(\mathrm{v})\end{array}\right]\end{array}$

The corresponding $\mathrm{Z}$-singular matrices are as follows.

\begin{tabular}{|c|c|c|}
\hline Property & $\underline{\text { Rule }}$ & Axiom \\
\hline Reflexitivity & $\left(\rho_{\mathrm{z}}\right) \overline{\mathrm{z} \doteq \mathrm{z}}$ & $\mathrm{z} \doteq \mathrm{z}$ \\
\hline Symmetry & $\left(\sigma_{\mathrm{z}}\right) \frac{\mathrm{z} \doteq \mathrm{z}}{\mathrm{z} \doteq \mathrm{z}}$ & $\left(\begin{array}{c}\mathrm{z} \doteq \mathrm{z} \\
\downarrow \\
\mathrm{z} \doteq \mathrm{z}\end{array}\right)$ \\
\hline Transitivity & $\left(\tau_{\mathrm{z}}\right) \frac{\mathrm{z} \doteq \mathrm{z} \quad \mathrm{z} \doteq \mathrm{z}}{\mathrm{z} \doteq \mathrm{z}}$ & {$\left[\begin{array}{c}(\mathrm{z} \doteq \mathrm{z} \wedge \mathrm{z} \doteq \mathrm{z}) \\
\downarrow \\
\mathrm{z} \doteq \mathrm{z}\end{array}\right.$} \\
\hline Congruence & $\left(\kappa_{\mathrm{z}}\right) \frac{\mathrm{z} \doteq \mathrm{z} p(\mathrm{z})}{\mathrm{p}(\mathrm{z})}$ & {$\left[\begin{array}{c}(\mathrm{z} \doteq \mathrm{z} \wedge \mathrm{p}(\mathrm{z})) \\
\downarrow \\
\mathrm{p}(\mathrm{z})\end{array}\right.$} \\
\hline
\end{tabular}

Thus, except for the case of reflexivity, the singular case is trivial.

We may now provide propositional explanations for the above three examples. The situation is as follows:

1. the matrix $\mathrm{z} \doteq \mathrm{z}$ is the equality axiom $\mathrm{z} \doteq \mathrm{z}$;

2. the matrix $\neg \mathrm{Z} \doteq \mathrm{z}$ is not derivable from the equality axiom $\mathrm{z} \doteq \mathrm{z}$ 
3. the matrix $\mathrm{y} \doteq \mathrm{z}$ has singulary version $\mathrm{z} \doteq \mathrm{z}$, which is (derivable from) $\mathrm{z} \doteq \mathrm{z}$.

We thus have the following characterizations for provable existential sentences in Classical, Intuitionistic or Minimal Logics with equality $\doteq$ (cf. Theorem 2.1).

Theorem 3.1. The following assertions are equivalent for a matrix $M(\mathrm{y}, \mathrm{z})$.

$\left(P_{1} E S\right)$ The existential sentence is provable in predicate logic: $\vdash_{1} \exists \mathrm{y} \exists \mathrm{z} M(\mathrm{y}, \mathrm{z})$.

$\left(P_{1} E V\right)$ The existential variant is a theorem: $\vdash_{1} \exists \mathrm{y} \exists \mathrm{z}[M(\mathrm{y}, \mathrm{z}) \vee M(\mathrm{z}, \mathrm{z})]$.

$\left(D_{0} S M\right)$ The singular matrix is derivable in propositional logic from the propositional letter $\mathrm{z} \doteq \mathrm{z}: \mathrm{z} \doteq \mathrm{z} \vdash{ }_{0} M(\mathrm{z}, \mathrm{z})$.

$\left(P_{1} U V\right)$ The universal variant is a theorem: $\vdash_{1} \forall \mathrm{y} \forall \mathrm{z}[M(\mathrm{y}, \mathrm{z}) \vee M(\mathrm{z}, \mathrm{z})]$.

The argument is much as in Section 2. The only difference lies in the propositional reduction. ${ }^{8}$ It now becomes as follows:

$$
\begin{gathered}
\emptyset \\
\exists \\
\exists \mathrm{y} \exists \mathrm{z} M(\mathrm{y}, \mathrm{z})
\end{gathered} \quad \begin{gathered}
\mathrm{z} \doteq \mathrm{z} \\
\Pi_{\mathrm{z}} \\
M(\mathrm{z}, \mathrm{z})
\end{gathered}
$$

So, a predicate-logic proof of $\exists \mathrm{y} \exists \mathrm{z} M(\mathrm{y}, \mathrm{z})$ now has the following form:

$$
\begin{gathered}
\overline{\mathrm{z} \dot{\bar{\Pi}}_{\mathrm{z}}} \\
(\exists \mathrm{I})^{2} \frac{M(\mathrm{z}, \mathrm{z})}{\exists \mathrm{y} \exists \mathrm{z} M(\mathrm{y}, \mathrm{z})}
\end{gathered}
$$

${ }^{8}$ Alternatively, one can simplify the singular matrix $M(\mathrm{z}, \mathrm{z})$ to $M(\mathrm{z}, \mathrm{z})_{\top}$ by replacing each occurrence of $\mathrm{z} \doteq \mathrm{z}$ by $T$. Then, the propositional reduction becomes $\vdash_{0} M(\mathrm{z}, \mathrm{z})_{\top}$. 


\section{Universal axioms}

We now turn to the case of universal axioms as hypotheses.

We begin with simple examples of propositional reduction. Given the matrices $P(\mathrm{v}, \mathrm{w})$ and $M(\mathrm{y}, \mathrm{z})$, their singular versions are $P(\mathrm{z}, \mathrm{z})$ and $M(\mathrm{z}, \mathrm{z})$, respectively.

- Assume that the matrices do not have equality and that we have a propositional derivation $\Pi_{0}$ of $M(\mathrm{z}, \mathrm{z})$ from $P(\mathrm{z}, \mathrm{z})$. We then have a predicate-logic derivation $\Pi$ as follows:

$$
\begin{gathered}
(\forall \mathrm{E})^{2} \frac{\forall \mathrm{v} \forall \mathrm{w} P(\mathrm{v}, \mathrm{w})}{P(\mathrm{z}, \mathrm{z})} \\
\Pi_{0} \\
(\exists \mathrm{l})^{2} \frac{M(\mathrm{z}, \mathrm{z})}{\exists \mathrm{y} \exists \mathrm{z} M(\mathrm{y}, \mathrm{z})}
\end{gathered}
$$

Hence, $\forall \mathrm{v} \forall \mathrm{w} P(\mathrm{v}, \mathrm{w}) \vdash_{1} \exists \mathrm{y} \exists \mathrm{z} M(\mathrm{y}, \mathrm{z})$.

- For the case with equality, assume that we have a propositional derivation $\Pi_{0}$ of $M(\mathrm{z}, \mathrm{z})$ from $\mathrm{z} \doteq \mathrm{z}$ and $P(\mathrm{z}, \mathrm{z})$. We then have a predicate-logic derivation $\Pi$ as follows:

$$
\begin{array}{cc}
\overline{\mathrm{z} \doteq \mathrm{z}} \quad(\forall \mathrm{E})^{2} \frac{\forall \mathrm{v} \forall \mathrm{w} P(\mathrm{v}, \mathrm{w})}{P(\mathrm{z}, \mathrm{z})} \\
\Pi_{0} \\
M(\mathrm{z}, \mathrm{z}) \\
\hline \mathrm{y})^{2} \frac{\mathrm{y} \exists M(\mathrm{y}, \mathrm{z})}{}
\end{array}
$$

Hence, $\forall \mathrm{v} \forall \mathrm{w} P(\mathrm{v}, \mathrm{w}) \vdash_{1} \exists \mathrm{y} \exists \mathrm{z} M(\mathrm{y}, \mathrm{z})$.

Thus, we can see that:

- the propositional derivability of singular matrices $\mathrm{z} \doteq \mathrm{z}, P(\mathrm{z}, \mathrm{z}) \vdash_{0} M(\mathrm{z}, \mathrm{z})$,

- yields the predicate-logic derivability $\forall \mathrm{v} \forall \mathrm{w} P(\mathrm{v}, \mathrm{w}) \vdash_{1} \exists \mathrm{y} \exists \mathrm{z} M(\mathrm{y}, \mathrm{z})$

The converse can be seen by propositional reduction (cf. Section 2). If we replace every variable by $\mathrm{z}$ and erase all quantifiers, we transform derivations: 


$$
\begin{aligned}
& \forall \mathrm{x} \forall \mathrm{v} \forall \mathrm{w} R(\mathrm{x}, \mathrm{v}, \mathrm{w}) \quad \mathrm{z} \doteq \mathrm{z} \quad R(\mathrm{z}, \mathrm{z}, \mathrm{z}) \\
& \exists \mathrm{y} \exists \mathrm{z} M(\mathrm{y}, \mathrm{z}) \quad M(\mathrm{z}, \mathrm{z})
\end{aligned}
$$

So, a derivation of $\exists \mathrm{y} \exists \mathrm{z} M(\mathrm{y}, \mathrm{z})$ from $\forall \mathrm{x} \forall \mathrm{v} \forall \mathrm{w} R(\mathrm{x}, \mathrm{v}, \mathrm{w})$ has the following form:

$$
\begin{array}{cc}
\overline{\mathrm{z} \doteq \mathrm{z}} \quad(\forall \mathrm{E})^{3} \frac{\forall \mathrm{x} \forall \mathrm{v} \forall \mathrm{w} R(\mathrm{x}, \mathrm{v}, \mathrm{w})}{R(\mathrm{z}, \mathrm{z}, \mathrm{z})} \\
(\exists \mathrm{I})^{2} \frac{\Pi_{\mathrm{z}}}{M(\mathrm{z}, \mathrm{z})} \\
\exists \mathrm{y} \exists \mathrm{z} M(\mathrm{y}, \mathrm{z})
\end{array}
$$

Now, let the singular $\mathrm{z}$ translation of a set $\Delta$ of universal sentences be the set consisting of their singular $\mathrm{z}$ matrices: $\Delta_{\mathrm{z}}:=\{R(\mathrm{z}, \ldots, \mathrm{z}): \forall \mathrm{x} \ldots \forall \mathrm{w} R(\mathrm{x}, \ldots, \mathrm{w}) \in \Delta\}{ }^{9}$

We then have the following characterizations for existential consequences of universal sentences in Classical, Intuitionistic or Minimal Logics with equality $\doteq(\mathrm{cf}$. Theorem 3.1).

Theorem 4.1. Given a set $\Delta$ of universal sentences, the following assertions are equivalent for a matrix $M(\mathrm{y}, \mathrm{z})$.

$\left(D_{1} E S\right)$ The existential sentence is derivable in predicate logic from the set $\Delta$ of universal sentences: $\Delta \vdash_{1} \exists \mathrm{y} \exists \mathrm{z} M(\mathrm{y}, \mathrm{z})$.

$\left(D_{1} E V\right)$ The existential variant is derivable in predicate logic from the set $\Delta$ of universal sentences: $\Delta \vdash_{1} \exists \mathrm{y} \exists \mathrm{z}[M(\mathrm{y}, \mathrm{z}) \vee M(\mathrm{z}, \mathrm{z})]$.

$\left(D_{0} S M\right)$ The singular matrix is derivable in propositional logic from $\mathrm{z} \doteq \mathrm{z}$ and singular $\mathrm{z}$ translation of $\Delta: \mathrm{z} \doteq \mathrm{z}, \Delta_{\mathrm{z}} \vdash_{0} M(\mathrm{z}, \mathrm{z})$.

$\left(D_{1} U V\right)$ The universal variant is derivable in predicate logic from the set $\Delta$ of universal sentences: $\Delta \vdash_{1} \forall \mathrm{y} \forall \mathrm{z}[M(\mathrm{y}, \mathrm{z}) \vee M(\mathrm{z}, \mathrm{z})]$.

${ }^{9}$ The axioms for equality (cf. Section 3 ) form a set $\Lambda$ of universal sentences. Note that $\Lambda_{\mathrm{z}}$ is equivalent to $\{\mathrm{z} \doteq \mathrm{z}\}$. 


\section{Existential hypotheses}

We now briefly consider the addition of existential axioms as hypotheses.

We begin with a simple examples to introduce the ideas. Given a binary relation $\mathrm{r}$, one may represent the fact that $a$ is related to $b$ via $\mathrm{r}$ by an arrow pointing from $a$ to $b: a \rightarrow b$. Now, let us call an element cyclic when there is an arrow from it to itself: $c \rightarrow c$. Also, call an element bicyclic when there is a path of length 2 from it to itself: $b \rightarrow d \rightarrow b$, for some $d$. Let us use $C$ and $B$ for the sets of cyclic and bicyclic elements, respectively.

From the existence of cyclic elements, one can establish the existence of bicyclic elements, i.e. $C \neq \emptyset$ yields $B \neq \emptyset$. One can argue as follows. Since there exists cyclic elements, we have some $c \in C$. Now, as $c \in C$, we have $c \rightarrow c$; so we also have the path $c \rightarrow c \rightarrow c$ , whence $c \in B$. This argument actually establishes $C \subseteq B$, which is sufficient. ${ }^{10}$

We claim that establishing such inclusion is the only way to proceed. The intuitive idea is that, for all we know, the assumed cyclic element $c$ may be the only element of the universe. More precisely, consider unary predicates $\mathrm{p}$ and $\mathrm{q}$. If $\exists \mathrm{up}(\mathrm{u}) \models \exists \mathrm{zq}(\mathrm{z})$, the we claim that the inclusion $\forall \mathrm{u}(\mathrm{p}(\mathrm{u}) \rightarrow \mathrm{q}(\mathrm{u}))$ is valid. Indeed, otherwise, one would have a structure $\mathfrak{M}$ where $\mathrm{p} \subseteq \mathrm{q}$ fails, i.e., for some $a \in M, a \in \mathrm{p}$ but $a \notin \mathrm{q}$. Now, consider the sub-structure $\mathfrak{N}$, with universe $N:=\{a\}$. In this structure $\mathfrak{N}$, we have $\mathrm{p} \neq \emptyset$ but $\mathrm{q}=\emptyset$, so $\mathfrak{N}=\exists$ up $($ u $)$ but $\mathfrak{N} \not \neq \exists$ zq $(\mathrm{z})$.

Now, let us examine some examples of existential consequences of existential hypotheses (without equality, for simplicity).

Given matrices $P(\mathrm{u})$ and $M(\mathrm{z})$, consider the sentences $\exists \mathrm{u} P(\mathrm{u})$ and $\exists \mathrm{z} M(\mathrm{z})$.

$\left(D_{I} E S\right)$ Consider the predicate-logic derivability

$\exists \mathrm{u} P(\mathrm{u}) \vdash_{1} \exists \mathrm{z} M(\mathrm{z})$.

Here, the assumption is $P \neq \emptyset$; so there is some element in $P$, call it $\mathrm{u}$ . Much as above, for all we know, u may very well be the only element

${ }^{10}$ This kind of argument appears often in Algebra: from the existence of (right) neuters, one establishes the existence of idempotents, by showing that every (right) neuter is an idempotent. 
of the universe. As we wish to have $M \neq \emptyset$, we must have $\mathrm{u} \in M$. This leads to the propositional reduction, which provides $\mathrm{u}$ as a witness for $\exists \mathrm{z} M(\mathrm{z})$.

$\left(D_{0} M\right)$ We have the propositional-logic derivability of matrices:

$P(\mathrm{u}) \vdash_{0} M(\mathrm{u})$.

This propositional reduction leads to the universal explanation.

$\left(P_{1} U C\right)$ The universal matrix connection is a theorem:

$\vdash_{1} \forall \mathrm{u}(P(\mathrm{u}) \rightarrow M(\mathrm{u}))$.

Clearly, this universal connection yields the predicate-logic derivability $\left(D_{1} E S\right)$.

We thus have the equivalence between the assertions $\left(D_{1} E S\right),\left(D_{0} M\right)$ and $\left(P_{1} U C\right)$.

For a another example, consider the existential sentences $\exists \mathrm{v} \exists \mathrm{w} R(\mathrm{v}, \mathrm{w})$ and $\exists \mathrm{z} M(\mathrm{z})$, as well as a set $\Delta$ of universal sentences.

$\left(D_{1} E S\right)$ Consider the predicate-logic derivability:

$$
\Delta, \exists \mathrm{v} \exists \mathrm{w} R\left(\begin{array}{c}
\mathrm{v} \\
\mathrm{w}
\end{array}\right) \vdash_{1} \exists \mathrm{z} M(\mathrm{z})
$$

Now, the assumption is $R \neq \emptyset$. So, there is some pair of elements, say $\mathrm{u}$ and $\mathrm{w}$, in $\mathrm{u}$. Much as above, for all we know, $\mathrm{u}$ and $\mathrm{w}$ might very well be the only elements of the universe. ${ }^{11}$ As we wish to have $M \neq \emptyset$, we must have $\mathrm{u} \in M$ or $\mathrm{w} \in M$. This leads to the propositional reduction, giving $\mathbf{u}$ and $\mathrm{w}$ as (alternative) witnesses for $\exists \mathrm{z} M(\mathrm{z})$.

$\left(D_{0} M\right)$ We have the propositional-logic derivability of matrices:

$$
\underset{\Delta_{\mathrm{w}}}{\Delta_{\mathrm{v}}}, R\left(\begin{array}{c}
\mathrm{v} \\
\mathrm{w}
\end{array}\right) \vdash_{0}\left(\begin{array}{c}
M(\mathrm{v}) \\
\mathrm{V} \\
M(\mathrm{w})
\end{array}\right)
$$

This propositional reduction leads to the universal explanation.

(D UC) We have the universal consequence connecting the matrices:

${ }^{11}$ Recall that we have no constants or functions. 


$$
\Delta \vdash_{1} \forall \mathrm{v} \forall \mathrm{w}\left[R\left(\begin{array}{c}
\mathrm{v} \\
\mathrm{w}
\end{array}\right) \rightarrow\left(\begin{array}{c}
M(\mathrm{v}) \\
\mathrm{V} \\
M(\mathrm{w})
\end{array}\right)\right]
$$

Clearly, this universal connection yields the predicate-logic derivability $\left(D_{1} E S\right)$.

For the case with equality, to obtain the propositional reduction it suffices to add the appropriate reflexivity axioms.

Theorem 5.1. The following assertions are equivalent for existential sentences $\exists \mathrm{u} P(\mathrm{u}), \exists \mathrm{v} \exists \mathrm{w} R(\mathrm{v}, \mathrm{w})$ and $\exists \mathrm{z} M(\mathrm{z})$ and a set $\Delta$ of universal sentences.

( $D_{l}$ ES) Predicate-logic derivability:

$$
\begin{gathered}
\exists \mathrm{u} P(\mathrm{u}) \\
\Delta, \quad \exists \mathrm{v} \exists \mathrm{w} R\left(\begin{array}{c}
\mathrm{v} \\
\mathrm{w}
\end{array}\right){ }^{{ }_{1} \exists \mathrm{z} M(\mathrm{z})}
\end{gathered}
$$

$\left(D_{0} M\right)$ Propositional-logic derivability of matrices:

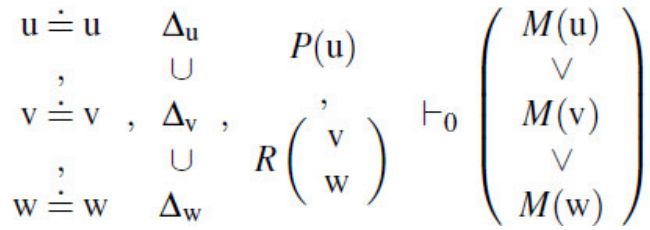

$\left(D_{1} U C\right)$ Predicate-logic derivability of the universal matrix connection:

$$
\Delta \vdash_{1} \forall \mathrm{u} \forall \mathrm{v} \forall \mathrm{w}\left[\left(\begin{array}{c}
P(\mathrm{u}) \\
\wedge \\
R\left(\begin{array}{c}
\mathrm{v} \\
\mathrm{w}
\end{array}\right)
\end{array}\right) \rightarrow\left(\begin{array}{c}
M(\mathrm{u}) \\
\vee \\
M(\mathrm{v}) \\
\vee \\
M(\mathrm{w})
\end{array}\right)\right]
$$

The method for constructing the propositional reduction and the universal connection should be clear by now. We consider distinct existentially quantified variables (by resorting to alphabetical variants, if necessary), which gives the witnesses. Then, the existential hypotheses give their matrices. For the existential conclusion, we 
replace each one of its variables by the witnesses. For instance, consider the predicate-logic derivability

$$
\exists \mathrm{u} P(\mathrm{u})
$$

$$
\Delta, \quad \exists \mathrm{v} \exists \mathrm{w} R\left(\begin{array}{c}
\mathrm{v} \\
\mathrm{w}
\end{array}\right) \stackrel{\vdash_{1} \exists \mathrm{y} \exists \mathrm{z} M(\mathrm{y}, \mathrm{z})}{ }
$$

Its universal connection is as follows:

$$
\Delta \vdash_{1} \forall \mathrm{u} \forall \mathbf{v} \forall \mathrm{w}\left[\left(\begin{array}{c}
P(\mathrm{u}) \\
\wedge \\
R\left(\begin{array}{c}
\mathrm{v} \\
\mathrm{w}
\end{array}\right)
\end{array}\right) \rightarrow\left(\begin{array}{c}
\mathrm{u}, \mathrm{u}) \\
\vee \\
M(\mathrm{u}, \mathrm{v}) \\
\vee \\
M(\mathrm{u}, \mathrm{w}) \\
\vee \\
\vdots \\
M(\mathrm{w}, \mathrm{v}) \\
\vee \\
M(\mathrm{w}, \mathrm{w})
\end{array}\right)\right]
$$

We can extend these ideas to the existential formulas derivable from universal formulas. For the case with equality we have the following characterization.

Theorem 5.2. The following assertions are equivalent for matrices $R(\mathrm{u}, \mathrm{v})$ and $M(\mathrm{x}, \mathrm{z})$ and a set $\Delta$ of universal sentences.

$\left(D_{1} S\right)$ Predicate-logic derivability of sentences:

$$
\Delta, \exists \mathrm{u} \forall \mathrm{v} R\left(\begin{array}{c}
\mathrm{u} \\
\mathrm{v}
\end{array}\right) \vdash_{1} \forall \mathrm{x} \exists \mathrm{z} M\left(\begin{array}{c}
\mathrm{x} \\
\mathrm{z}
\end{array}\right)
$$

$\left(D_{1} F\right)$ Predicate-logic derivability of formulas:

$$
\Delta, \forall \mathrm{v} R\left(\begin{array}{c}
\mathrm{u} \\
\mathrm{v}
\end{array}\right) \vdash_{1} \exists \mathrm{z} M\left(\begin{array}{l}
\mathrm{x} \\
\mathrm{z}
\end{array}\right)
$$

$\left(D_{0} M\right)$ Propositional-logic derivability of matrices: 


$$
\begin{array}{ccc}
\mathrm{u} \doteq \mathrm{u} & \Delta_{\mathrm{u}} & R\left(\begin{array}{c}
\mathrm{u} \\
\mathrm{u}
\end{array}\right) \\
\mathrm{x} \doteq \mathrm{x} & , \quad \Delta_{\mathrm{x}} & R\left(\begin{array}{c}
\mathrm{u} \\
\mathrm{x}
\end{array}\right)
\end{array} \vdash_{0}\left(\begin{array}{c}
M\left(\begin{array}{c}
\mathrm{x} \\
\mathrm{u}
\end{array}\right) \\
\mathrm{V} \\
M\left(\begin{array}{c}
\mathrm{x} \\
\mathrm{x}
\end{array}\right)
\end{array}\right)
$$

$\left(D_{1} U C\right)$ Predicate-logic derivability of the universal matrix connection:

$$
\Delta \vdash_{1} \forall \mathrm{u} \forall \mathrm{x}\left[\left(\begin{array}{c}
R\left(\begin{array}{c}
\mathrm{u} \\
\mathrm{u}
\end{array}\right) \\
\wedge \\
R\left(\begin{array}{l}
\mathrm{u} \\
\mathrm{x}
\end{array}\right)
\end{array}\right) \rightarrow\left(\begin{array}{c}
M\left(\begin{array}{l}
\mathrm{x} \\
\mathrm{u}
\end{array}\right) \\
\mathrm{V} \\
M\left(\begin{array}{l}
\mathrm{x} \\
\mathrm{x}
\end{array}\right)
\end{array}\right)\right]
$$

\section{Conclusion}

We now review our results, commenting on them and on some possible extensions.

Our aim in this paper has been to provide some substance and evidence for the idea that logic should not have existential theorems, by showing that existence in First-order Logic satisfies two general principles:

1. no existential conclusion without (perhaps alternative) witnesses, and

2. no existential conclusion without universal explanation.

This aim has been attained through several theorems relating existential validities to universal validities and propositional reducts.

First, we review the relationships established here regarding existential derivability (not excluding empty universes). Here $\Delta$ is a set of universal sentences.

(UH) Existential sentences derivable from universal sentences can be characterized by derivability of the corresponding universal variants. 
$\begin{array}{cc}\text { Existential sentence } & \Delta \vdash_{1} \exists \mathrm{z}_{1} \ldots \exists \mathrm{z}_{n} M\left(\mathrm{z}_{1}, \ldots, \mathrm{z}_{n}\right) \\ \text { iff } & \\ \text { Universal variant } & \Delta \vdash_{1} \forall \mathrm{z}_{1} \ldots \forall \mathrm{z}_{n}\left[\begin{array}{c}M\left(\mathrm{z}_{n}, \ldots, \mathrm{z}_{n}\right) \\ \vee \\ M\left(\mathrm{z}_{1}, \ldots, \mathrm{z}_{n}\right)\end{array}\right]\end{array}$

(EH) Existential sentences derivable from existential sentences can be characterized by derivability of the corresponding universal connections.

(EH1) Single existential hypothesis: the universal connection from hypothesis to conclusion provides a witness. ${ }^{12}$

$$
\begin{array}{cc}
\text { Existential sentence } & \Delta, \exists \mathrm{u} A(\mathrm{u}) \vdash_{1} \exists \mathrm{z} G(\mathrm{z}) \\
\text { iff } & \\
\text { Universal connection } & \Delta \vdash_{1} \forall \mathrm{u}[A(\mathrm{u}) \rightarrow G(\mathrm{u})]
\end{array}
$$

(EH1) Two existential hypotheses: the universal connection from hypotheses to conclusion provides alternative witnesses.

We can characterize the first-order derivability

$$
\text { Existential sentence } \quad \Delta, \exists \mathrm{u} A(\mathrm{u}), \exists \mathrm{w} D(\mathrm{w}) \vdash_{1} \exists \mathrm{z} G(\mathrm{z})
$$

by means of the connection (for Minimal, Intuitionistic and Classical Logic)

$$
\text { Universal connection } \quad \Delta \vdash_{1} \forall \mathrm{u} \forall \mathrm{w}\left[\left(\begin{array}{c}
A(\mathrm{u}) \\
\wedge \\
D(\mathrm{w})
\end{array}\right) \rightarrow\left(\begin{array}{c}
G(\mathrm{u}) \\
\vee \\
G(\mathrm{w})
\end{array}\right)\right]
$$

${ }^{12}$ For instance, from the existence of angels one can derive the existence of gods iff one can prove that every angel is a god. 
For the case of Classical Logic, we have a stronger characterization by means of alternative connections. ${ }^{13}$

$$
\text { Alternative connections } \quad \Delta \vdash_{1}\left[\begin{array}{c}
\forall \mathrm{u}(A(\mathrm{u}) \rightarrow G(\mathrm{u})) \\
\vee \\
\forall \mathrm{w}(D(\mathrm{w}) \rightarrow G(\mathrm{w}))
\end{array}\right]
$$

For sentences and formulas, we can summarize these results as follows.

(ES) An existential sentence $E S$ gives rise to a universal sentence $U S$, so that

$$
\Delta \vdash_{1} E S \text { iff } \Delta \vdash_{1} U S
$$

Thus, we have our first general principle:

$\underline{\text { no }}$ existential conclusion without (perhaps alternative) witnesses.

(EF) For the case of an existential sentence $E S$ together with universal formulas $U F$, we have a simple quantifier-free formula $U F^{*} \rightarrow E F^{*}$, such that

$$
\Delta, U F \vdash_{1} E F \text { iff } \Delta \vdash_{1} U F^{*} \rightarrow E F^{*}
$$

Thus, we have our second general principle:

$\underline{\text { no }}$ existential conclusion without universal explanation.

We now comment on these results and on some possible extensions.

True, one could argue that all these results are limited in an important sense: they are obtained for a pure first order language, i.e., for a first order language without constant and function symbols. As mentioned in the introduction, given constant and function symbols, unless we assume some form of partiality, there is no way to avoid two typical existential validities, namely:

\footnotetext{
${ }^{13}$ For instance, from the existence of angels and demons one can derive the existence of gods iff one can prove that every angel is a god or every demon is a god.
} 
(Cnst) $\exists \mathrm{zz} \doteq \mathrm{c} \quad$ and $\quad(F n c) \exists \mathrm{x} \exists \mathrm{y} \mathrm{y} \doteq \mathrm{f}(\mathrm{x})$

A possible answer to this kind of criticism can be formulated as follows.

- The language of pure logic is really that of first-order logic without constant and function symbols.

- The above existential validities should be viewed - rather than as theorems of logic - as mere expressions of two general semantical desiderata:

names must denote and functions must be total.

Although some of the results obtained in this paper can be extended to a first-order language with constant and function symbols, we think it is appropriate to bear in mind here the final version of our slogan: Pure Logic cannot establish existence unless unavoidable.

As future work in this connection, we would like to mention two other analogous slogans we are now examining, namely the following ones.

- There are no necessary existential properties.

- There are no necessary possibilities.

The extension of some of the main results of this paper to properties/relations and modalities could very well provide an interesting starting point towards a systematic treatment for the general issue of existence in logic.

Paulo A. S. Veloso Federal University of Rio de Janeiro

Luiz Carlos Pereira Pontifical Catholic University of Rio de Janeiro

E. Hermann Haeusler Pontifical Catholic University of Rio de Janeiro ${ }^{14}$

${ }^{14}$ Research partly sponsored by the Brazilian agencies CNPq and FAPERJ. 


\section{References}

Chavineau, Jean. 1979. La logique moderne ( $2^{\mathrm{e}}$ édition). Paris: PUF (Coll. "Que sais-je?" 745).

Ebbinghaus, H.-D., Flum, J. \& Thomas, W. 1984. Mathematical Logic. Berlin: Springer-Verlag.

Enderton, Herbert B. 1972. A Mathematical Introduction to Logic. New York: Academic Press.

Hume, David. Dialogues on Natural Religion. London: Penguin Classics, 1990.

Kant, Immamuel. Lógica. Rio de Janeiro: Tempo Brasileiro (Biblioteca Tempo Universitário 93), 1992.

Mendelson, Elliot. 1966. Introduction to Mathematical Logic. Princeton: D. van Nostrand (repr.).

Orenstein, Alex. 1973. On explicating existence in terms of quantification. In Logic and Ontology, ed. by Munitz, Milton K. New York: NYU Press.

Quine, W V O. 1954. Quantification in the empty domain. Journal of Symbolic Logic 19: 3 (177-179).

Shoenfield, Joseph R. 1967. Mathematical Logic. Reading: Addison-Wesley.

van Dalen, Dirk. 1989. Logic and Structure (2nd edition, 3rd printing). Berlin: Springer-Verlag.

Veloso, Paulo A. S., Pereira, Luiz Carlos \& Haeusler, Edward H. 2009. Validades existenciais e enigmas relacionados. Dois Pontos. 